\title{
Willingness to Pay for Assisted Reproductive Technologies by Pastoral Herd Owners in Southern Rangelands of Kenya
}

Fredrick Odiwuor Agutu ( $\sim$ agutufredricks@gmail.com )

Egerton University Faculty of Agriculture https://orcid.org/0000-0002-4065-4178 James Ombiro Ondiek

Egerton University Faculty of Agriculture

Samuel Mwanzia Mbuku

Kenya Agricultural \& Livestock Research Organization

Bockline Omedo Bebe

Egerton University Faculty of Agriculture

\section{Research Article}

Keywords: Assisted Reproductive Technologies, Willingness to Pay, Pastoral herd owners, Double bounded dichotomous choice, contingent valuation

Posted Date: November 11th, 2021

DOI: https://doi.org/10.21203/rs.3.rs-1028142/v1

License: (9) This work is licensed under a Creative Commons Attribution 4.0 International License. Read Full License 


\title{
Willingness to Pay for Assisted Reproductive Technologies by Pastoral Herd Owners in Southern
}

Rangelands of Kenya

\author{
Fredrick Odiwuor Agutu*1, James Ombiro Ondiek ${ }^{1}$, Samuel Mwanzia Mbuku², Bockline Omedo Bebe ${ }^{1}$ \\ ${ }^{1}$ Department of Animal Sciences, Egerton University, P.O. Box 536, 20115 Egerton, Kenya \\ ${ }^{2}$ Kenya Agricultural and Livestock Research Organization, Veterinary Science Research Institute, Muguga \\ North, P.O. Box. 32, 00902 Kikuyu, Kenya \\ *Corresponding author: agutufredricks@ gmail.com https://orcid.org/0000-0002-4065-4178
}

\begin{abstract}
Uptake of Assisted Reproductive Technologies (ARTs) can widen and accelerate access to quality breeding stock under pastoral systems, but user participation without subsidy is uncertain when the herders have to meet the direct cost. Analysing willingness to pay (WTP) for ARTs may provide insights into potential uptake of ARTs when development agencies withdraw subsidies and private entrepreneurs take up the service delivery. This study estimated WTP for ARTs among 130 pastoral herd owners participating in Sahiwal cattle breed upgrading program implemented in Transmara Sub County in the southern rangelands of Kenya. The average WTP was KES 3,643 (USD 33.4), equivalent to 21.4\% premium with reference to base price (KES 3,000) (USD 27.5). Sixty-seven percent of the pastoral herd owners expressed WTP above the hypothesized market price, twice more than those expressing WTP below the hypothesized market price (33\%). The first choice attributes influencing the WTP for ARTs were high milk yield (62\%), high value calves (37\%), and high growth rates $(1 \%)$. Gender was the only socioeconomic factor significantly $(\mathrm{P}<0.005)$ influencing WTP, with men expressing higher WTP than women (KES 3,870 (USD 35.5) versus KES 3,223 (USD 26.6). The results indicate a high likelihood of pastoral herd owners continuing to access and use ARTs at own cost, which provides opportunities for private sector participation in ARTs delivery and upscaling to increase access to superior Sahiwal genetic resources in pastoral herds. This will need putting in place policy interventions supportive of efficient ARTs delivery mechanisms.
\end{abstract}

Keywords: Assisted Reproductive Technologies, Willingness to Pay, Pastoral herd owners, Double bounded dichotomous choice, contingent valuation

\section{Introduction}

Livestock production in the Arid and Semi-arid lands (ASALs) provide pastoral communities with important livelihood benefits, both tangible (meat, milk) and non-tangible (financing, insurance and dowry). Development agencies in Kenya prioritize investments towards increasing the tangible benefits through upgrading indigenous cattle to an adaptable and more productive Sahiwal cattle breed under rangelands where climate is increasingly variable and changing. The Sahiwal cattle breed is principally a dual-purpose (meat and milk) breed adaptable to the Kenyan pastoral rangelands (Ilatsia et al., 2012). Here, the demand for improved Sahiwal bulls and heifers outstrip the supply (Mbuku et al., 2019). This situation emanates from multiple challenges limiting optimal utilization of the Sahiwal cattle as a livelihood improvement strategy. Supply of quality breeding stock is insufficient because of overreliance on a limited number of superior bulls initially provided by progressive breeding farms, predominantly the National Sahiwal Stud (NSS) and private ranches (Ilatsia et al., 2012). These breeding farms largely utilize closed nucleus breeding schemes that deploy natural bull service. This breeding 
strategy has been associated with increasing inbreeding levels and loss of genetic diversity among Sahiwal cattle population in Kenya - and will be tragic, if remains unchecked (Ilatsia et al., 2012; Mbuku et al., 2019).

Effective selection efforts for resilient and productive animals are required. Continued bull services could prove expensive as they are associated with risks of disease carriers, injurious to young heifers, increasing inbreeding levels and loss of genetic diversity with intense use (Mbuku et al., 2019). To increase access to high quality breeding stock, development agencies are supporting upscaling the use of a wide range of ARTs in the southern rangelands of Kenya (Khainga, 2015; Kebebe et al., 2017). The ARTs include artificial insemination (AI) using frozen semen, in vitro fertilization (IVF) and Multiple ovulation and embryo transfer (MOET) (Kios et al., 2018; Gicheha et al., 2019). Though use of ARTs offer comparative advantage over bull service in widening access to quality breeding stock for Sahiwal cattle upgrading, continued user participation post subsidy from the government and development agencies is uncertain when they have to meet the direct cost. For example, a previous study of AI utilization in ASALs (Narok county), observed a higher level of awareness about AI services among pastoralists (70\%), but those still using bull services as breeding method were predominating (Khainga, 2015). Continued use of bull services was partly attributed to preference for bull service (Janssentapken et al., 2006). Previous studies indicate that farmers often make decisions on adoption of new technologies based on awareness levels and enhanced efficiency in delivery, which is likely to influence their WTP for ARTs. The WTP for ARTs expressed by pastoralists should provide insight into continued use of ARTs when development agencies withdraw subsidy support and require that private entrepreneurs take up the service delivery. This study therefore estimated the WTP for ARTs to access superior genetic resources among pastoral herd owners. This information should interest development agencies and private service providers in the provision of sustainable breeding programs within pastoral production systems in Kenya.

\section{Materials and methods}

\section{Study site}

The study was carried among the Maasai herd owners engaged in ranching, nomadic, or agro-pastoralism and utilizing a mix of pure and crossbreeds of Maasai zebu, Boran and Sahiwal breeds for livelihood benefits (Ilatsia et al., 2011). Pastoral livelihood predominates in this southern Kenya rangelands of Transmara South Subcounty, Narok County (Khainga et al., 2018). The study sites were Lolgorian and Pusanki divisions located between Latitude $0^{\circ} 50^{\prime}$ and $1^{\circ} 50^{\prime}$ 'South and Longitude $34^{\circ} 35^{\prime}$ and $35^{\circ} 14^{\prime}$ East (GoK, 2008) (Figure 1).

\section{Sampling procedure}

The study targeted 150 households comprising of both program beneficiaries and non-beneficiaries determined from Cochran's proportionate sample size formula (Mugenda \& Mugenda, 2003):

$$
\boldsymbol{n}=\frac{z^{2} p q}{e^{2}}
$$

where $\mathrm{n}=$ sample size, $\mathrm{z}$ is desired confidence interval level set at 1.96 for $95 \%$ confidence interval, $\mathrm{p}$ is the proportion of a characteristic of the population with Sahiwal cattle breed, $q=(1-p)$, and $e$ is the error margin allowable for detecting a difference in the sample set at 0.05 . In computation, the $\mathrm{P}$ was set to 0.051 being proportion $=\left(\frac{2,573}{50,132}\right)$, of total number of Lolgorian and Pusanki households to households within Transmara West Sub-county (KNBS, 2019) having at least one Sahiwal cow (pure or crossbred). 


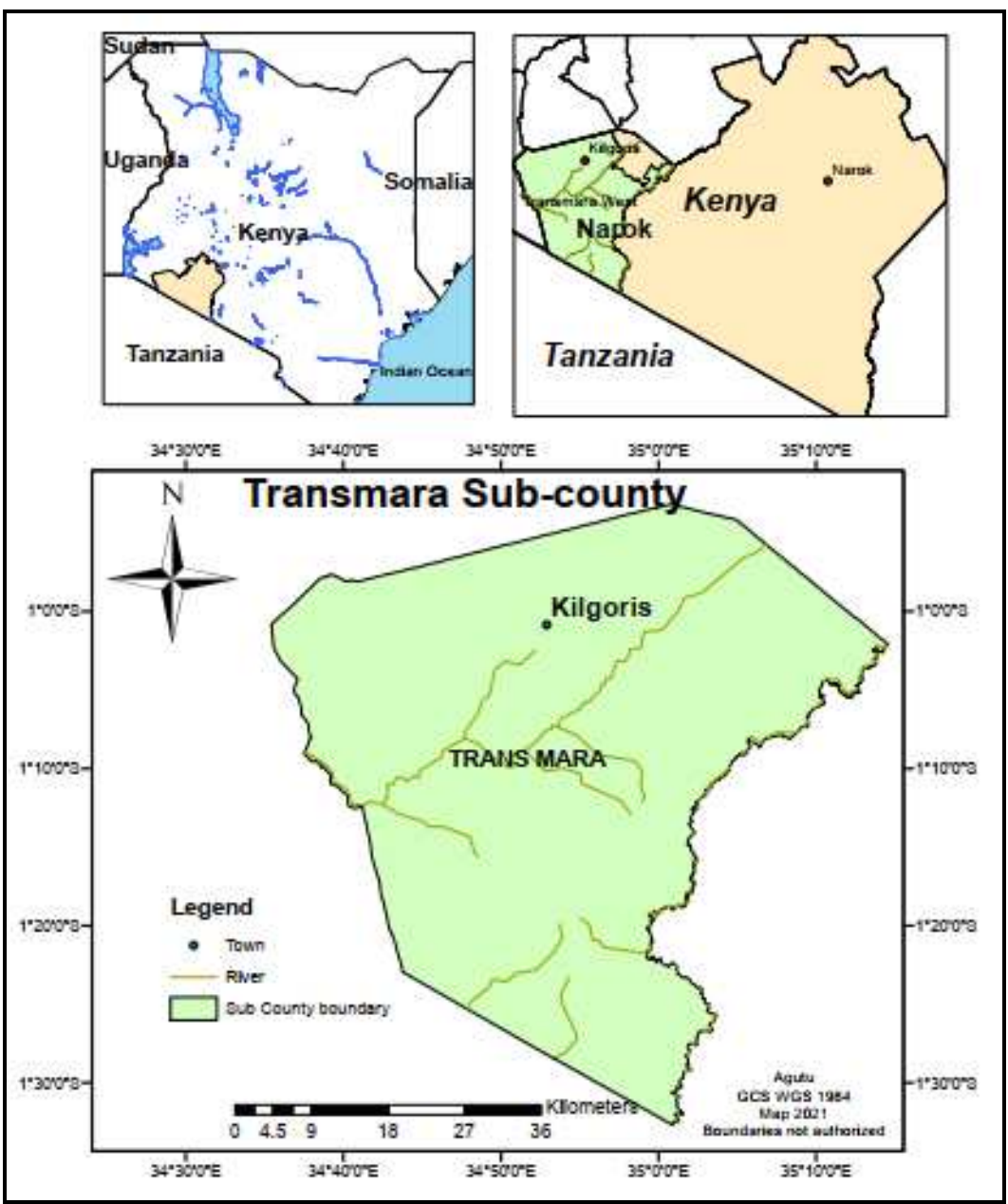

Figure 1: Map indicating location of study area

\section{Analytical framework}

The WTP was analysed using double bounded dichotomous choice contingent valuation model (CVM), applying the analytical framework of Hanemann et al., (1991). This model uses hypothesized bid levels that reflect the cost of accessing the service as the basis for calculating the mean WTP and given that the herd owners were aware of the ARTs but unable to attach true value to use of ARTs, close-ended questions approach was adopted.

The herd owner was initially asked if he/she was willing to pay an amount say ' $\mathrm{B}_{\mathrm{i}}$ ' for the provision of ARTs services per animal served. The level of the second bid level was contingent upon the response to the first bid; "higher than the initial bid if the response was 'yes' and this assumed that the $B_{i} \leq W T P<\infty$ ", or "lower if the response was 'no' and this assumed that the $0 \leq \mathrm{WTP}<\mathrm{B}_{\mathrm{i}}$ '. The subsequent bids played an important role in placing an upper and lower bound on the respondents' unobserved true WTP (Alberini and Cooper, 2000). Four possible outcomes can be obtained from the double bounded dichotomous model. These are presented as $y y, y n, n y$ and $n n$ where $y y$ implies that both answers are 'yes' (WTP is higher than the upper bid) and $y n$ implies first answer was 'yes' followed by 'no' (WTP is between initial bid and the upper bid). On the other hand, ny implies a 'no' answer followed by 'yes'(WTP is between lower bid and the initial bid) and $n n$ implies 'no' answer in both (WTP is between zero and the lower bid) (Hanemann et al., 1991). The possible outcomes and inferences from double bounded dichotomous choice questions on WTP are presented in Table 1. 


\begin{tabular}{ll}
\hline Inferences & Description \\
\hline$B_{i}$ & Initial bid price/ hypothesized cost for a good or service \\
$0<W T P<B_{i}$ & If the respondents answers no to the first bid \\
$B_{i}<W T P<\infty$ & If the respondents answers yes to the first bid \\
$B_{i}<W T P<B_{i}^{u}$ & If the respondent answers yes to the first bid and no to second \\
$B_{i}^{u}<W T P<\infty$ & If the respondent answers yes to the first and second bids \\
$B_{i}^{d}<W T P<B_{i}$ & If the respondent answers no to the first and yes to second \\
$0<W T P<B_{i}^{d}$ & If the respondent answers no to the first and second bids \\
\hline
\end{tabular}
$B_{i=}^{u}$ Second higher if answer to initial bid was yes; $B_{i}^{d}=$ Second higher if answer to initial bid price was no. Source: Lopez-Feldman, (2012).

The respondent was therefore assumed to make decisions following possible discrete outcomes, that is; $\mathrm{WTP}=0$ if $\mathrm{P} \leq 0$; and WTP $=1$ if $\mathrm{P}>0$ where WTP is 0 if the respondent is not willing to pay for the offered bid price and 1, if he/she is willing to pay the bid price for accessing ARTs. The dependent variable (WTP) was therefore hypothesized to be influenced by a set of socio-economic factors attributed to the respondents (Table 2). Regression analysis was further used in establishing the relationship between identified independent factors against the dependent factor using the equation below;

$$
W T P_{i}=\alpha+\beta_{1} Z_{i}+\ldots \ldots .+\beta_{n} Z_{n}+\varepsilon_{i} \text { and } i=1 \ldots, n
$$

where, $W T P_{i}$ is the probability of the $i$ th respondent's willingness to pay the hypothesized bid price for accessing ARTs, $Z_{\tilde{i}_{m} n}$ are the set of socioeconomic variables of the respondent, $\varepsilon_{i}$ is the random error term, while $\alpha$ and $\beta$ are parameters of the model to be estimated.

Table 2: Various socioeconomic indicator variable definitions and their measurements

\begin{tabular}{llcc}
\hline Variable & Definition & Measurement & Expected sign \\
\hline Gender & Gender of herd owner & Categorical & + \\
Age & Age of respondent & Continuous & + -- \\
Education & Education level of herd owner & Categorical & + \\
Livelihood source & Main livelihood source for herd owner & Categorical & + \\
Production System & Production system for cattle keeping & Categorical & + \\
Grazing area & Number of acres for grazing livestock & Continuous & + +- \\
Farming Experience & Number of years keeping Cattle & Continuous & + +- \\
& & & \\
Market distance & Distance to main market for inputs & Continuous & + -- \\
First choice attribute & Choices by herd owners related to attributes of & Categorical & + \\
& ARTs & &
\end{tabular}

Data analysis

112 The data collected with questionnaires was first processed in Microsoft Excel spreadsheet to sort, edit and clean then transferred to Statistical Packages Social Sciences (SPSS) version 26 for statistical computing. A linear 
114 regression modelling with backward elimination procedures was used to retain only variables that had

115 significant influence on the WTP for ARTs out of all the hypothesized independent variables (Table 2).

116 Results

\section{Characteristics of the herd owners}

118 From a target of 150 respondents, 130 were reached in the survey with 126 providing complete responses for 119 analysis. The four (4) excluded were incomplete or inconsistent responses on one or more variables. Table 3 120 presents the summary descriptive characteristics and mean WTP for ARTs based on gender, age, education

121 level, primary livelihood source, production system, grazing area, farming experience, market distance and first

122 choice attributes of using ARTs by the sample herd owners. Males (65\%) dominated over females, with

123 majority (68\%) being between 31 and 60 years old and having attained basic primary education (55\%). Their

124 primary livelihood source was livestock based (74\%), with more than half practicing nomadic pastoralism and 125 accessing less than 50 acres of grazing land. Majority (68\%) had livestock farming experience of less than 25

126 years and chose high milk yield (60\%) relative to other attributes as the first attribute of choice for accessing 127 ARTs.

128 The mean WTP was KES 3,643.86 and was about 20\% higher $(\mathrm{P}<0.05)$ among males $($ KES 3,870$)$ than among 129 females (KES 3,233). Within production systems, the mean WTP was 3\% higher though insignificant (P>0.05), 130 among those in agro-pastoralism than those in ranching (KES 3,657 vs KES 3,560). High milk yield as first 131 choice attribute had 3\% and 5\% higher WTP compared to high value calves and high growth rates preferences 132 respectively (Table 3 ).

133 Table 3: Estimated costs $(\text { KES) })^{\text {a }}$ on mean WTP values based on gender, production system, age and first 134 choice attributes by pastoral herd owners

\begin{tabular}{|c|c|c|c|c|c|c|}
\hline Factor & Level & $\mathbf{N}(\%)$ & $\begin{array}{c}\text { WTP above } \\
\text { base price } \\
\text { n }(\%)\end{array}$ & $\begin{array}{c}\text { WTP below } \\
\text { base price } \\
\text { n }(\%)\end{array}$ & Mean WTP \pm SD & $\begin{array}{l}\text { P- } \\
\text { value }\end{array}$ \\
\hline \multirow[t]{3}{*}{ Gender } & Male & $82(65)$ & $60(71)$ & $21(50)$ & $3,870.37 \pm 1139.67$ & \multirow[t]{3}{*}{0.04} \\
\hline & Female & $44(35)$ & $24(29)$ & $21(50)$ & $3,233.33 \pm 1218.42$ & \\
\hline & Overall & $126(100)$ & $84(67)$ & $42(33)$ & $3,642.86 \pm 1203.22$ & \\
\hline \multirow[t]{4}{*}{ Age (years) } & Below 30 & $37(29)$ & $24(29)$ & $13(31)$ & $3,586.49 \pm 1164.80$ & \multirow[t]{4}{*}{0.716} \\
\hline & $31-60$ & $85(68)$ & $58(69)$ & $27(64)$ & $3,687.06 \pm 1219.17$ & \\
\hline & Above 61 & $4(3)$ & $2(2)$ & $2(5)$ & $3,225.00 \pm 1447.70$ & \\
\hline & Overall & $126(100)$ & $84(67)$ & $42(33)$ & $3,642.86 \pm 1203.22$ & \\
\hline \multirow{5}{*}{$\begin{array}{l}\text { Education } \\
\text { level }\end{array}$} & None & $57(45)$ & $34(40)$ & $23(55)$ & $3,459.65 \pm 1,269.54$ & \multirow[t]{5}{*}{0.319} \\
\hline & Primary & $41(33)$ & $31(37)$ & $10(24)$ & $3,892.68 \pm 1,055.55$ & \\
\hline & Secondary & $16(13)$ & $10(12)$ & $6(14)$ & $3,518.75 \pm 1,1,39.13$ & \\
\hline & Tertiary & $12(9)$ & $9(11)$ & $3(7)$ & $3,825.00 \pm 1400.08$ & \\
\hline & Overall & $126(100)$ & $84(67)$ & $42(33)$ & $3,642.86 \pm 1203.22$ & \\
\hline \multirow{4}{*}{$\begin{array}{l}\text { Primary } \\
\text { livelihood } \\
\text { source }\end{array}$} & Livestock farming & $93(74)$ & $63(75)$ & $30(71)$ & $3651.61 \pm 1,184.92$ & \multirow[t]{4}{*}{0.245} \\
\hline & Mixed farming & $31(25)$ & $19(23)$ & $12(29)$ & $3529.03 \pm 1,261.00$ & \\
\hline & Employment & $2(1)$ & $2(2)$ & $0(0)$ & $5,000.00 \pm 0.00$ & \\
\hline & Overall & $126(100)$ & $84(67)$ & $42(33)$ & $3,642.86 \pm 1203.22$ & \\
\hline \multirow{2}{*}{$\begin{array}{l}\text { Production } \\
\text { Systems }\end{array}$} & Ranching & $5(4)$ & $2(2)$ & $3(7)$ & $3,560.00 \pm 1320.23$ & \multirow[t]{2}{*}{0.987} \\
\hline & Nomadic & $107(85)$ & $73(87)$ & $34(81)$ & $3,644.86 \pm 1192.37$ & \\
\hline
\end{tabular}




\begin{tabular}{|c|c|c|c|c|c|c|}
\hline \multirow{7}{*}{$\begin{array}{l}\text { Grazing area } \\
\text { (acres) }\end{array}$} & \multicolumn{6}{|l|}{ Pastoralism } \\
\hline & Agro-pastoralism & $14(11)$ & $9(11)$ & $5(12)$ & $3,657.14 \pm 1337.46$ & \\
\hline & Overall & $126(100)$ & $84(67)$ & $42(33)$ & $3,642.86 \pm 1203.22$ & \\
\hline & $<50$ & $100(79)$ & $70(83$ & $30(71)$ & $3,725.00 \pm 1,153.68$ & \multirow[t]{4}{*}{0.130} \\
\hline & $51-100$ & $16(13)$ & $8(10)$ & $8(19)$ & $3,075.00 \pm 1,364.06$ & \\
\hline & $>101$ & $10(8)$ & $6(7)$ & $4(10)$ & $3,730.00 \pm 1,307.28$ & \\
\hline & Overall & $126(100)$ & 84 (67) & $42(33)$ & $3,642.86 \pm 1203.22$ & \\
\hline Farming & $<25$ & $86(68)$ & $59(70)$ & $27(64)$ & $3,740.70 \pm 1,176.37$ & \multirow[t]{4}{*}{0.240} \\
\hline \multirow{3}{*}{$\begin{array}{l}\text { Experience } \\
\text { (Years) }\end{array}$} & $25-50$ & $39(31)$ & $25(30)$ & $14(33)$ & $3,464.10 \pm 1,248.05$ & \\
\hline & $>51$ & $1(1)$ & $0(0)$ & $1(3)$ & $2.200 .00 \pm 0$ & \\
\hline & Overall & $126(100)$ & $84(67)$ & $42(33)$ & $3,642.86 \pm 1203.22$ & \\
\hline \multirow{4}{*}{$\begin{array}{l}\text { Market } \\
\text { distance } \\
(\mathrm{Km})\end{array}$} & $<10$ & $89(71)$ & $62(74)$ & $27(64)$ & $3,624.72 \pm 1,143.98$ & \multirow[t]{4}{*}{0.361} \\
\hline & $11-20$ & $24(19)$ & $16(19)$ & $8(19)$ & $3,891.67 \pm 1,348.40$ & \\
\hline & $>21$ & $13(10)$ & $6(7)$ & $7(17)$ & $3,307.69 \pm 1,323.17$ & \\
\hline & Overall & $126(100)$ & $84(67)$ & $42(33)$ & $3,642.86 \pm 1203.22$ & \\
\hline \multirow{4}{*}{$\begin{array}{l}\text { First Choice } \\
\text { attributes }\end{array}$} & High milk yield & $76(60)$ & $52(62)$ & $24(57)$ & $3,681.58 \pm 1,225.80$ & \multirow[t]{4}{*}{0.987} \\
\hline & High value calves & $49(39)$ & $31(37)$ & $18(43)$ & $3,585.71 \pm 1.190 .06$ & \\
\hline & High growth rates & $1(1)$ & $1(1)$ & $0(0)$ & $3,500.00 \pm 0$ & \\
\hline & Overall & $126(100)$ & $84(67)$ & $42(33)$ & $3,642.86 \pm 1203.22$ & \\
\hline
\end{tabular}

$135{ }^{a}$ One US dollar = KES 109 at the time of study

136 In general, $67 \%$ and $33 \%$ of the herd owners expressed WTP above and below the bid prices respectively.

137 Seventy one percent (71\%) and $29 \%$ of male and female herd owners expressed WTP value above the base price

138 while an equal proportion (50\%), declined the first bid with WTP below the bid price (Table 4). Middle aged

139 herd owners (between 31-60 years) expressed 69\% and 64\% above and below bid WTP price respectively

140 relative to above 61 years who expressed $2 \%$ and 5\% above and below bid WTP price respectively. Higher milk

141 yield attribute as first choice for using ARTs by herd owners had $62 \%$ above the bid WTP and $57 \%$ below the

142 bid WTP; high value calves above $37 \%$ and below is $43 \%$; and high growth rate above the bid WTP at $1 \%$.

143 In the regression analysis, only gender was retained as socio-economic factor of significant $(\mathrm{P}<0.05)$ influence

144 on the level of WTP for utilizing ARTs by herd owners (Table 5).

145 Table 5: Results for regression analysis of factors influencing WTP for ARTs

\begin{tabular}{|c|c|c|c|c|}
\hline & Full model & & Reduced model & \\
\hline Variables & Estimate & P Value & Estimate & P Value \\
\hline Intercept & 5147.168 & 0.0001 & 4507.407 & 0.0001 \\
\hline Gender & -779.277 & 0.002 & -637.037 & 0.004 \\
\hline Age & -14.112 & 0.301 & & \\
\hline Education level & -53.802 & 0.674 & & \\
\hline Main Livelihood & 173.006 & 0.446 & & \\
\hline Production System & -12.086 & 0.961 & & \\
\hline Grazing Area & -0.929 & 0.608 & & \\
\hline Farming Experience & 0.146 & 0.991 & & \\
\hline Distance to market & 6.388 & 0.576 & & \\
\hline
\end{tabular}


148 Presently, pastoral herd owners in southern Kenyan rangelands are meeting the growing demand for quality 149 breeding stock of Sahiwal heifers and bulls through subsidies provided by development agencies. This access to 150 breeding technology is unsustainable because when subsidy is withdrawn, the access would have to revert to private sector delivery mechanism. The WTP for utilizing ARTs was evaluated amongst pastoralists using double bounded contingent evaluation method based on hypothetical bid prices and subsequent follow-up bids of either above or below the bids depending on responses from initial bids (Drucker et al., 2001; Bett et al., 2009; Ilatsia et al., 2011). The findings indicate that seven in ten $(67 \%)$ of the pastoral herd owners would be willing to pay above the initial bid price, which reflects a high likelihood of pastoral herd owners meeting direct cost on future access to ARTs. This suggests good prospects of continued access of Sahiwal semen for breeding purposes post subsidy support and participation of private sector in the delivery of the ARTs to herd owners. Higher WTP for ARTs could mean that pastoral herd owners are satisfied with the off springs from ARTS under their management conditions. This could be attributed to the continuous sensitization and practical demonstration forums that the programme implemented in the area. The findings corroborates those of Atsiaya et al. (2018) who reported that $66 \%$ of the herd owners expressed WTP above the bid prices. Khainga et al. (2018) as well reported over half of the sample (52\%) of pastoral herd owners expressing willing to pay above the initial bid price for artificial insemination (AI) in Kajiado and Narok Counties. In their study, Khainga et al. (2018) focused on perception of AI use by pastoralists. In contrast, the present study had advantage of practical demonstrations and service delivery undertaken to enhance the community awareness levels on ARTs use. This therefore, implies that awareness and capacity building through trainings, practical demonstrations and extension service provision, is essential for successful introduction and adoption of ARTs in pastoral production systems. This is in line with Dehinenet et al. (2014) who reported that awareness through livestock trainings and demonstrations, increase farmers' probability of adopting and paying for improved dairy technologies. This is a relevant matter for extension service when planning to upscale ARTs adoption in pastoral production systems.

The average WTP was an equivalent of $21.4 \%$ premium on the base price of the ARTs. The higher preminum rate demonstrate the community desire to continue utilizing ARTs towards upgrading their herd. In this regard, the agro-pastralists expressed a 3\% higher WTP than ranchers (KES 3,657 versus KES 3,560), which is contrary to expectations. The ranchers, being commercial oriented, would be expected to express higher WTP for ARTS than the agro and nomadic pastoralists. The awareness and farm-level demonstrations were directed to the agro and nomadic pastoralist, which could explain this observation. The premium rate reported in the study is in agreement with that observed by Khainga et al., (2018), who also reported $25.4 \%$ WTP premium on AI by pastorlist from Kajiado and Narok counties. The higher premium rate presents an opportunity to the private sector participation in ARTs delivery model. This will need supportive policy interventions that target delivering superior genetic materials to pastoral herd owners.

181 Gender was the only socioeconomic factor with significant $(\mathrm{P}<0.05)$ influence on WTP with men expressing $20 \%$ higher WTP than women (KES 3,870 versus KES 3,233). Partly, a higher proportion of males than females $(65 \%$ versus $35 \%)$ in the sample partly explains this. When gender differences are differentiated by first choice attribute, males expressed higher preferences for bull calves from use of ARTs to use for future breeding. Males perceived that, accessing a bull calf and raising the calf on farm to breeding age, would be cheaper than buying 
one from the research stations, ranches or model farms. Furthermore, they argued that raising a bull calve on farm, ensures more adaptability to the local environment and diseases as compared to bulls sourced outside the locality.

On the other hand, females considered higher milk production as their initial reason for WTP for ARTs. To explain this observation, women value milk to feed their families for food security and nutrition goals. This corroborates with reports of Kariuki et al. (2017) that women farmers express preferences for cows with higher milk potential. In other studies, female herders have been observed to trade some of the milk for family income to support other livelihood needs (Chawala et al., 2019). However, some studies report contrasting finding: Khainga et al., (2018) reported insignificant influence of gender on the WTP for AI in Kajiado and Narok Counties.

\section{Conclusions}

About two-thirds of the herd owners expressed WTP above the base price, indicating a higher likelihood of pastoral herd owners adopting ARTs for upgrading Sahiwal cattle breed without reliance on subsidies. This presents an opportunity for private sector participation in ARTs delivery and upscaling in pastoral herds. This will need putting in place policy interventions supportive of efficient ARTs delivery mechanisms for pastoral herd owners.

\section{Acknowledgements}

The authors would like to thank the joint financial support by Africa Centre of Excellence in Sustainable Agriculture and Agribusiness Management (CEESAM) and Dairy Genetics Project supported by the Government of Kenya through National Research Fund and led by the Kenya Agricultural and Livestock Research Organization (KALRO). Sincere gratitude also goes to the many pastoral herd owners in Transmara who shared with us their experiences and plight during the study.

Author contribution: Conceptualization: Fredrick Odiwuor Agutu, Samuel Mwanzia Mbuku, Bockline Omedo Bebe. Methodology; Fredrick Odiwuor Agutu, Samuel Mwanzia Mbuku, Bockline Omedo Bebe; writing original draft preparation: Fredrick Odiwuor Agutu. Formal analysis and investigation: Fredrick Odiwuor Agutu, James Ombiro Ondiek, Samuel Mwanzia Mbuku, Bockline Omedo. Review and editing: Fredrick Odiwuor Agutu, James Ombiro Ondiek, Samuel Mwanzia Mbuku, Bockline Omedo. Resources: James Ombiro Ondiek, Samuel Mwanzia Mbuku, Bockline Omedo. Supervision: James Ombiro Ondiek, Samuel Mwanzia Mbuku, Bockline Omedo Bebe

Funding: The work for this study was supported by joint funds from the Africa Centre of Excellence in Sustainable Agriculture and Agribusiness Management (CEESAM) program at Egerton university funded by the World Bank and, Dairy Genetics Project supported by the Government of Kenya through National Research Fund and led by the Kenya Agricultural and Livestock Research Organization (KALRO).

Data availability: The datasets generated during and/or analysed during the current study are available from the corresponding author on reasonable request.

\section{Code availability: N/A}

\section{Declarations}


Ethics approval: The study was approved by National Commission for Science, Technology and Innovation (NACOSTI); and Egerton University Research Ethics approval committee. The interviewed respondents gave their informed consent prior to their inclusion in the study

Consent to participate Verbal informed consent was obtained prior to the interview

\section{Consent for publication N/A}

Conflict of interest: The authors have no competing interests to declare that are relevant to the content of this article.

\section{References}

Alberini, A., \& Cooper, J. (2000). Applications of the contingent valuation method in developing countries: A survey, FAO Economic and Social Development Paper No. 146, Rome.

Atsiaya, G. O., Wati, L. N., Ingasia, O. A., \& Lagat, J. K. (2018). Smallholder Farmers ' Willingness to Pay for Insurance Against Climate Variability Effects in Arid Land Areas of Kenya. Journal of Environment and Earth Science, 8(11), 52-59. https://www.iiste.org/Journals/index.php/JEES/article/view/45049

Chawala, A. R., Banos, G., Peters, A., \& Chagunda, M. G. G. (2019). Farmer-preferred traits in smallholder dairy farming systems in Tanzania. Tropical Animal Health and Production, 51(6), 1337-1344. https://doi.org/10.1007/s11250-018-01796-9

Dehinenet, G., Mekonnen, H., Kidoido, M., Ashenafi, M., \& Bleich, E. G. (2014). The impact of dairy technology adoption on small holder dairy farmers livelihoods in selected zones of Amhara and Oromiya National Rgional States, Ethiopia. Global Journal of Agricultural Economics and Econometrics, 2(5), 126135.

Drucker, A. G., Gomez, V., \& Anderson, S. (2001). The economic valuation of farm animal genetic resources: A survey of available methods. Ecological Economics, 36(1), 1-18. https://doi.org/10.1016/S09218009(00)00242-1

Gicheha, M. G., Akidiva, I. C., \& Cheruiyot, R. Y. (2019). Genetic and economic efficiency of integrating reproductive technologies in cattle breeding programme in Kenya. Tropical Animal Health and Production, 51(2), 473-475. https://doi.org/10.1007/s11250-018-1689-1

Government of Kenya (GoK). (2008). Trans Mara District Development Plan (2002-2008). Nairobi: Government Printer.

Hanemann, M., Loomis, J., \& Kanninen, B. (1991). Statistical Efficiency of Double-Bounded Dichotomous Choice Contingent Valuation. American Journal of Agricultural Economics, 73(4), 1255-1263. https://doi.org/10.2307/1242453

Ilatsia, E. D., Roessler, R., Kahi, A. K., Piepho, H.-P., \& Zárate, V. (2012). Production objectives and breeding goals of Sahiwal cattle keepers in Kenya and implications for a breeding programme. Tropical Animal Health and Production, 44(3), 519-530. https://doi.org/10.1007/s11250-011-9928-8

Ilatsia, E. D., Roessler, R., Kahi, A. K., \& Valle Zárate, A. (2011). Breeding and conservation programmes for Sahiwal cattle genetic resources in the tropics: a review. Animal Genetic Resources/Ressources Génétiques animales/Recursos Genéticos Animales, 49, 65-74. https://doi.org/10.1017/s2078633611000336

Janssen-tapken, U., Kadarmideen, H. N., \& Rohr, P. Von. (2006). Cattle breeding strategies using genetic markers as a pathway for improving competitiveness of pastoral systems in Kenya. Paper Contributed to the Conference on Pastoralism and Poverty Reduction in East Africa: A Policy Research Conference, Nairobi, Kenya, June 27-28., 31. https://hdl.handle.net/10568/2514

Kariuki, C., Van Arendonk, J., Kahi, A., \& Komen, H. (2017). Multiple criteria decision-making process to derive consensus desired genetic gains for a dairy cattle breeding objective for diverse production systems. Journal of Dairy Science, 100, 4671-4682.

Kebebe, E. G., Oosting, S. J., Baltenweck, I., \& Duncan, A. J. (2017). Characterisation of adopters and nonadopters of dairy technologies in Ethiopia and Kenya. Tropical Animal Health and Production, 49(4), 681690. https://doi.org/10.1007/s11250-017-1241-8

Kenya National Bureau of Statistics (KNBS). (2019). 2019 Kenya Population and Housing Census: Volume II: Distribution of Population by Administrative Units. KNBS, Nairobi.: Vol. II.

Khainga, D. N. (2015). Adoption of assisted reproductive technologies and Sahiwal cattle breed and their 
impact on household farm income in Narok and Kajiado Counties of Kenya. MSc Thesis in Agricultural and Applied Economics, Department of Agricultural Economics, Egerton Unive. www.egerton.ac.ke insemination in arid and semi-arid lands of Kenya. Journal of Development and Agricultural Economics, 10(8), 262-270. https://doi.org/10.5897/JDAE2018.0920

Kios, D. K., Tsuma, V., \& Mutembei, H. (2018). Factors Affecting Adoption Of Embryo Transfer Technology In Dairy Cattle In Kenya. Advances in Social Sciences Research Journal, 5(8), 456-463. https://doi.org/10.14738/assrj.58.5047

Lopez-Feldman, A. (2012). Introduction to contingent valuation using Stata. MPRA Paper No. 41018. (Issue January). https://www.researchgate.net/publication/277834172\%0AIntroduction

Mbuku, S. M., Magothe, T. M., Mwangi, D., Egesa, P., \& Kihurani, D. (2019). Smallholder Farmers Access to Improved Sahiwal Cattle Genetics in Kenya: The Long Shadow. In Innovations to Harness the Potential of African Animal Agriculture in a Globalizing World. Paper Presented at the Proceedings of the 7th All Africa Conference on AnimaL Agriculture Held on July 29 to August 2, 2019 at Accra International Conference Cen.

Mugenda, O. M., \& Mugenda, A. G. (2003). Research Methods: Quantitative and Qualitative Approaches, ACTS Press, Nairobi, Kenya. 